[Original]

\title{
Transient Alpha-helical Structure during Folding of Src SH3 Domain at Subzero Temperatures
}

\author{
Zhijie QIN ${ }^{1,2}$, Sandip VYAS ${ }^{2}$, Anthony L. FINK ${ }^{2}$, Jinsong LI ${ }^{1}$ and Hiroshi KIHARA ${ }^{1 *}$ \\ ${ }^{1}$ Department of Physics, Kansai Medical University, 18-89 Uyama-Higashi, Hirakata, 573-1136 Japan \\ ${ }^{2}$ Department of Chemistry and Biochemistry, University of California at Santa Cruz, CA
}

\begin{abstract}
Substantial questions remain about the process of protein folding, including whether transient intermediates exist with significantly different secondary structure than the final fold. The src SH3 domain is a highly beta-rich structure with five betastrands. We report here a far-UV circular dichroism investigation of the refolding of His-tagged Src SH3 at subzero temperatures. We observed a transient $\alpha$-helix-rich intermediate, indicating that the early stages of protein folding can involve the formation of intermediates with very different structures from the final conformation.
\end{abstract}

Key words: Src SH3 domain, circular dichroism, protein folding, subzero temperature, alpha-helical burst

Abbreviations: CD; circular dichroism, EGOH; ethylene glycol, GuHCl; guanidine hydrochloride, src SH3; chicken src homology SH3 domain, UV; ultraviolet, PBS; phosphate-buffered saline.

\section{Introduction}

The underlying processes that determine how a protein folds into its native structure from the unfolded state are still substantially unknown. For example, there is some controversy regarding the folding mechanisms of small proteins and whether they follow a "framework" model in which the protein folding begins with local interaction of the polypeptide to form secondary structures ${ }^{1)}$, or a "hydrophobic collapse" model in which the unfolded polypeptide first collapses to a compact globule state $^{2)}$. As the folding of small proteins is very fast, it is difficult to monitor the early events of the folding process. We have established a subzero temperature stopped-flow system, coupled with circular dichroism, fluorescence and SAXS, and investigated the early events of the folding of two $\beta$-rich proteins, $\beta$ $\operatorname{lactoglobulin}^{3)}$ and ubiquitin ${ }^{4,5)}$. In both cases the $\beta$ rich proteins initially formed an $\alpha$-helix-rich inter-

\footnotetext{
* Corresponding author. Hiroshi Kihara phone: +81-72-856-2121, fax: +81-72-850-0733 e-mail: kihara@makino.kmu.ac.jp
}

mediate, even though there is no helix in their native structures. In the current work we investigated another all- $\beta$-stucture protein, the $\mathrm{Src} \mathrm{SH} 3$ domain, to monitor its folding processes at subzero temperatures.

SH3 domains are common small protein domains (approximately 60 amino acids) first identified in $\mathrm{Src}^{6)}$ and $\alpha$-spectrin ${ }^{7)}$. They are found in a number of proteins having distinct activities involved in signal transduction and cellular localization. Investigation of several SH3 domains has revealed the conserved structural features of these domains ${ }^{9,10)}$. The SH3 fold consists of two small orthogonal three stranded $\beta$-sheets with an associated irregular two-stranded sheet packing against each other in a sandwich form. The overall structure is stabilized by numerous hydrophobic interactions. The conserved aromatic residues gather on the top edge of the protein, forming a smooth platform bordered by loops containing acidic residues. This external region constitutes most of the peptide-binding site and has two hydrophobic pockets, which interact with the protruding side chains in the proline-rich motif. 
Src SH3 domains have been extensively studied as typical models for two-state folding proteins, including studies on the folding transition state and its structural origins using a combination of experimental results, computer simulations, and simple model calculations ${ }^{9,10)}$. These have revealed that the distal $\beta$-hairpin (strands 3 (residues 44-47) and 4 (residues 52-56)) is fully formed in the transition state, while the $\mathrm{N}$-terminal and $\mathrm{C}$-terminal regions are not folded. Also, the rate-limiting step in folding involves formation of the distal $\beta$ hairpin and the diverging turns. Furthermore, it has been reported that the folding of the src SH3 domain follows the single-pathway-based energy landscape picture of protein folding ${ }^{11)}$.

We report here a far-UV CD investigation of the refolding of Src SH3, at subzero temperatures. It was found that the all- $\beta$-structure protein formed a transient $\alpha$-rich intermediate during the early stages of folding.

\section{Materials and Methods}

\section{Src SH3}

The protein, with a His-tag, was expressed in a BL21 (DE3) cell line, from a plasmid, pET-15b, kindly supplied by David Baker, University of Washington, Seattle. Cells were lysed using sonication, centrifuged and the supernatant was loaded on a NiNTA Sepharose column for purification. The column was equilibrated with the following buffer: $20 \mathrm{mM}$ Tris pH 8.0, $200 \mathrm{mM} \mathrm{NaCl}, 5 \mathrm{mM}$ imidazole, $0.5 \mathrm{mM}$ PMSF, $2.5 \mathrm{mM}$ benzamidine. The protein was eluted using $400 \mathrm{mM}$ imidazole over 4-6 column volumes. Pooled protein fractions were dialyzed against $20 \mathrm{mM}$ Tris $\mathrm{pH} 8.0,200 \mathrm{mM} \mathrm{NaCl}$, and concentrated using an YM3 membrane under pressure. The protein were analyzed using SDS-PAGE (20\%) PhastGel. Analysis by ESI-MS showed a mass of 8680, the mass expected for the His-tagged src SH3. The concentration of SH3 was determined spectrophotometrically using an extinction coefficient of $\mathrm{E}_{280}=16500$ / $\mathrm{M} / \mathrm{cm}$.

\section{Equilibrium $C D$ measurements}

The samples were prepared in $50 \mathrm{mM}$ PBS buffer, $\mathrm{pH} 3.0$, with different concentrations of ethylene glycol (EGOH) and $\mathrm{GuHCl}$, where concentration of EGOH was shown by volume-to-volume ratio (v/v). The concentration of SH3 was $30 \mu \mathrm{M}$. Static CD measurements were performed at $4^{\circ} \mathrm{C}$ and $-20^{\circ} \mathrm{C}$ respectively with a spectropolarimeter specially designed by Unisoku Inc. Cuvettes of $1 \mathrm{~mm}$ path length were used in these measurements.

\section{Kinetic $C D$ measurements}

The SH3 domain was first unfolded in $50 \mathrm{mM}$ PBS, $\mathrm{pH} 3.0$, with $5.0 \mathrm{M} \mathrm{GuHCl}$, and was diluted 7 times with the refolding buffer $(0 \mathrm{M} \mathrm{GuHCl})$ so as to initiate the refolding. The final concentration of $\mathrm{GuHCl}$ is thus $0.7 \mathrm{M}$. The refolding process was monitored by ellipticity at $222 \mathrm{~nm}$. Measurements were repeated and accumulated to give a good signal/noise ratio. The averaged data were normalized to give molar ellipticity.

\section{Results}

Effect of ethylene glycol on Src SH3 secondary structure

The secondary structure of the Src SH3 domain was analyzed by circular dichroism spectroscopy for concentrations of ethylene glycol between 0 and $90 \%$ at $4^{\circ} \mathrm{C}$. From Figure 1 we can see that the SH3 domain shows similar spectra in the far-UV range both with and without ethylene glycol. The CD spectrum in the absence of ethylene glycol is almost the same as those in the presence of ethylene glycol. This suggests that the $\mathrm{SH} 3$ domain retains a nativelike structure even with the concentration of $\mathrm{EGOH}$ as high as $90 \%$.

Amplitudes of the molar ellipticity of the SH3 domain at $222 \mathrm{~nm}$ were plotted versus concentrations of ethylene glycol in Figure 2. This allows visualization of differences in $\alpha$-helix content of Src SH3 in the presence of various concentrations of ethylene glycol. The fact that no significant changes in ellipticity at $222 \mathrm{~nm}$ are observed in the presence of EGOH indicates that the presence of the cosolvent at concentrations lower than $90 \%$ does not change the sec- 


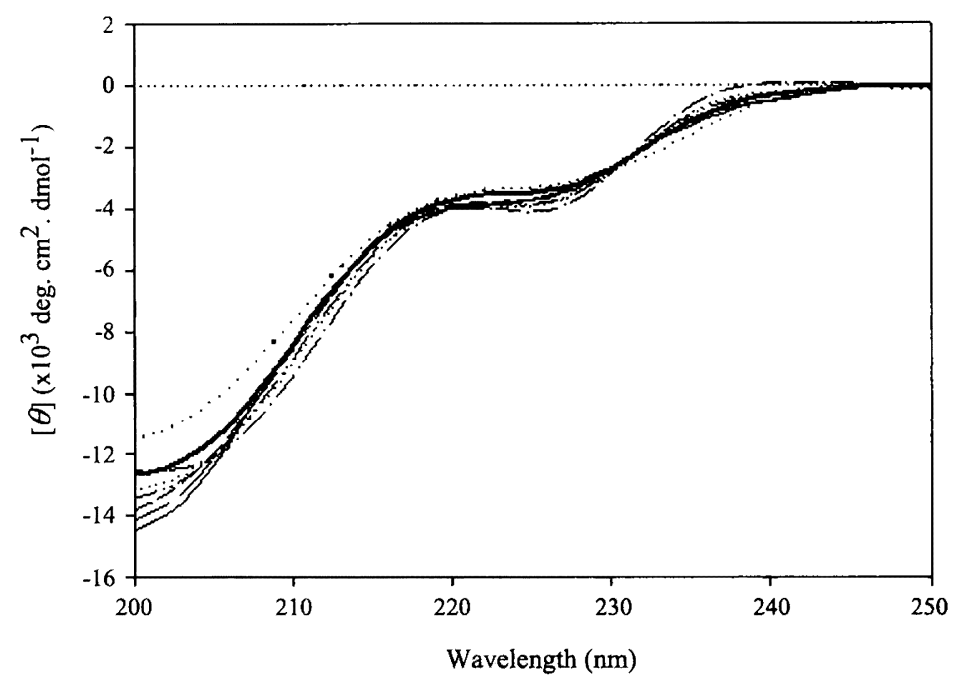

Fig. 1. The CD spectra of the Src SH3 domain as a function of ethylene glycol concentration, buffered with $40 \mathrm{mM}$ phosphate, $\mathrm{pH}$ 3.0. The EGOH concentration was raised in $10 \%$ increments from 0 to $90 \%$. The heavy solid line and heavy dotted line correspond to 70 and $90 \%$, respectively. The light dotted line is $0 \%$.

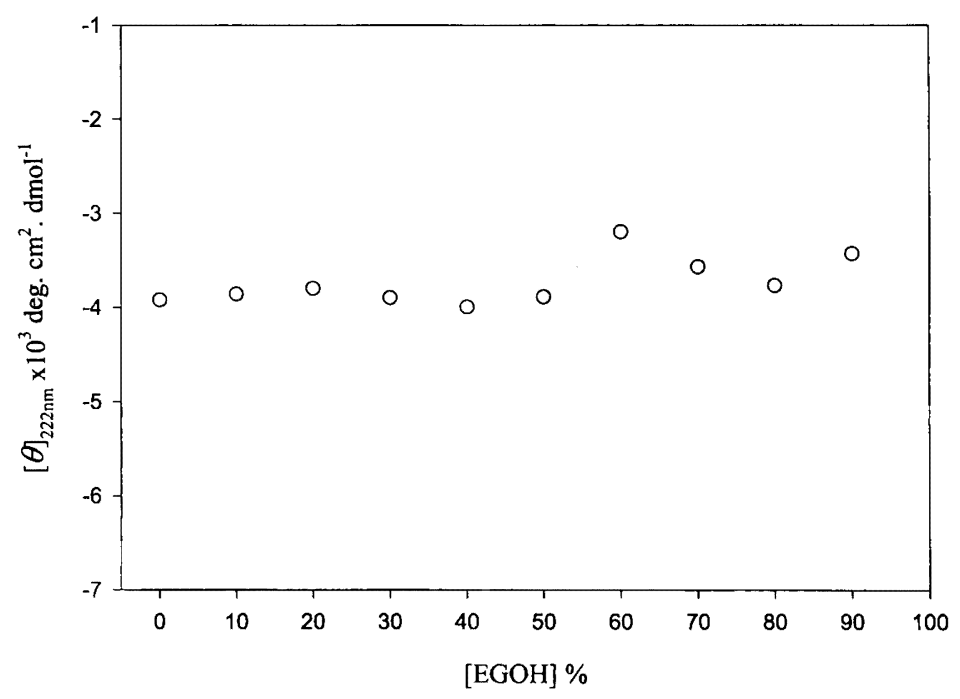

Fig. 2. Effect of EGOH on the circular dichroism of SH3 domain. Amplitudes of molecular ellipticity of SH3 domain at $222 \mathrm{~nm}$ wavelength were plotted versus concentrations of ethylene glycol.

ondary structure content of the SH3 domain. In the stopped-flow kinetics study we used $45 \% \mathrm{EGOH}$ as a cryosolvent, a system in which the protein should possess the same secondary structure as in its native state.

\section{Denaturant unfolding in $45 \%$ ethylene glycol}

Figure 3 shows the $\mathrm{GuHCl}$-induced equilibrium unfolding of Src SH3 in the presence of $45 \% \mathrm{EGOH}$ at $4^{\circ} \mathrm{C}$ and $-20^{\circ} \mathrm{C}$. The $\mathrm{GuHCl}$ titration reveals that the thermodynamic transition is well approximated by a two-state transition. SH3 is in the native state below $3 \mathrm{M} \mathrm{GuHCl}$ and in the unfolded state above 

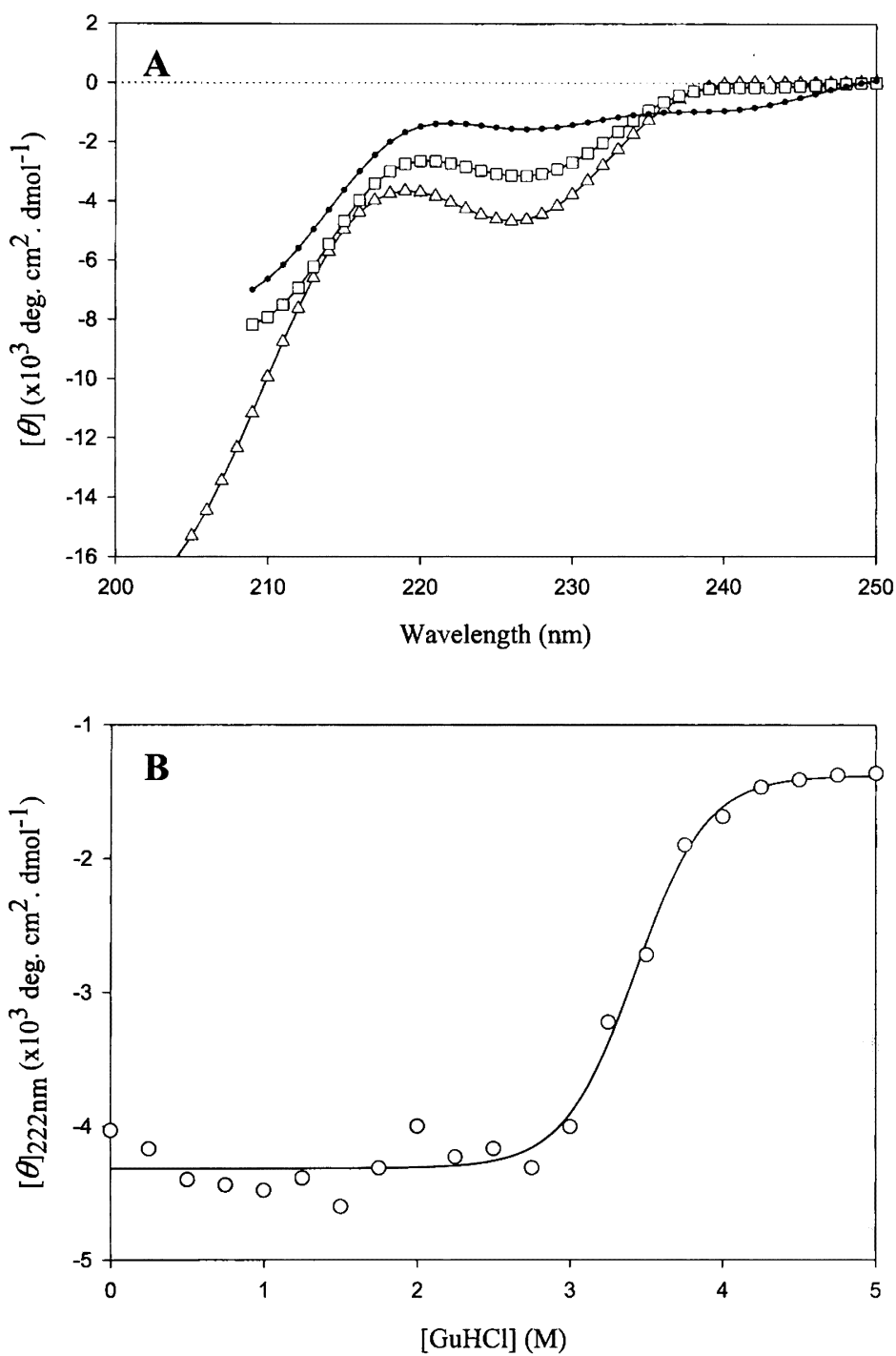

Fig. 3. The GuHCl-induced titration of the SH3 domain, in $45 \%-\mathrm{EGOH}, 40 \mathrm{mM}$ phosphate buffer, $\mathrm{pH} 3.0$ at, $4^{\circ} \mathrm{C}$. A; The $\mathrm{CD}$ spectra of src SH3 in different GuHCl concentration buffer, $0 \mathrm{M}$ (triangle $\triangle$ ), $3.5 \mathrm{M}$ (square $\square$ ) and $5 \mathrm{M}$ (dot $-\mathrm{B}$ ) $\mathrm{B}$ CD at $222 \mathrm{~nm}$ is used monitor the unfolding. The fit of data (solid curves) assumes a two state model.

$4.25 \mathrm{M} \mathrm{GuHCl}$. The transition midpoint $\left(\mathrm{C}_{\mathrm{m}}\right)$ at $4^{\circ} \mathrm{C}$ is $3.4 \mathrm{M}$, and slightly higher, at $3.6 \mathrm{M}$, at $-20^{\circ} \mathrm{C}$.

\section{Kinetics of refolding}

The ellipticity of SH3 at $222 \mathrm{~nm}$ in the process of refolding initiated by a concentration jump of $\mathrm{GuHCl}$ from $5.0 \mathrm{M}$ to $0.7 \mathrm{M}$ at $-20^{\circ} \mathrm{C}$ is shown in Fig. 4 . A large overshoot burst phase is shown, suggesting that an $\alpha$-helix-rich intermediate formed within the dead time of the stopped-flow. A conformational transition was observed with rate constant of $0.10 \mathrm{~s}^{-1}$ accompanied by a decrease in $\alpha$-helix content. The

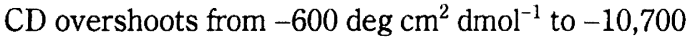
deg $\mathrm{cm}^{2} \mathrm{dmol}^{-1}$ at $222 \mathrm{~nm}$, and the conformational isomerization phase accounts for about $-64 \%$ of the signal. 

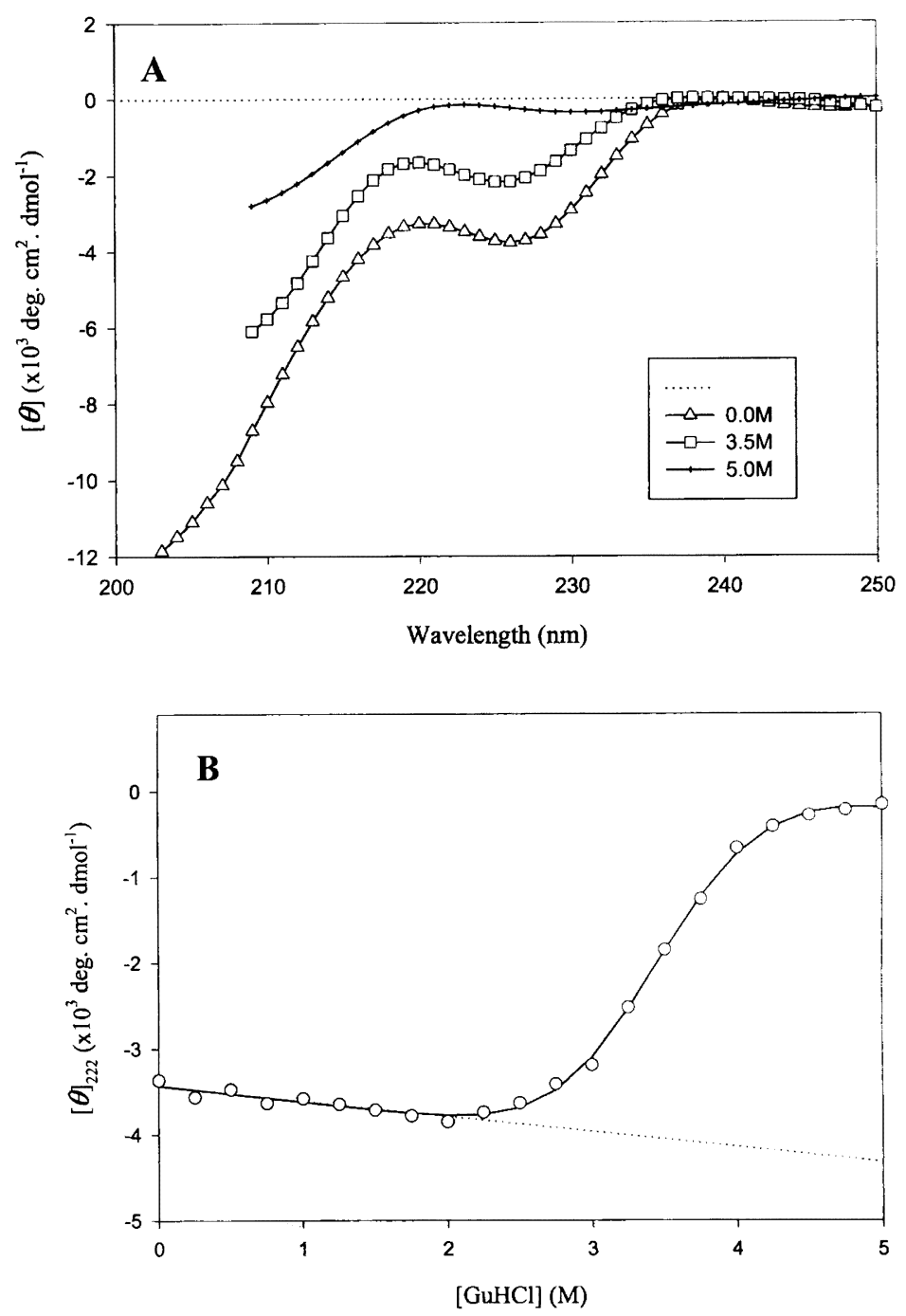

Fig. 4. The GuHCl-induced titration of the SH3 domain, in $45 \%-\mathrm{EGOH}, 40 \mathrm{mM}$ phosphate buffer, $\mathrm{pH} 3.0$ at, $-20^{\circ} \mathrm{C}$. A; The $\mathrm{CD}$ spectra of src SH3 with different concentration of $\mathrm{GuHCl}, 0 \mathrm{M}$ (triangle $\triangle$ ), $3.5 \mathrm{M}$ (square $\square$ ) and $5 \mathrm{M}$ (dot $\mathrm{O}$ ). B; $\mathrm{CD}$ at $222 \mathrm{~nm}$ is used monitor the unfolding. The fit of data (solid curves) assumes a two state model.

\section{Discussion}

Both theoretical calculation and experimental measurement indicate that formation of $\alpha$-helix from random coil of polypeptides is faster than that of $\beta$ sheet ${ }^{12-15)}$. The observation of non-native-like intermediates, accumulated during the early stages of refolding of $\beta$-rich proteins, with enhanced helical ellipticity raises a key question about the origin of protein folding: namely do "random coil" unfolded peptide chains collapse to a non-specific state with enhanced $\alpha$-helical structure?

Even though advances in rapid mixing techniques have made it possible to extend kinetic measurements well into the microsecond time-scale, most very early events in the folding from small proteins still fall within the dead time, especially the formation of secondary structure. We have reported the formation of non-native $\alpha$-helix-rich intermediates accumulated during the early stage of folding from two $\beta$-rich proteins: $\beta$-lactoglobulin and ubiquitin, 


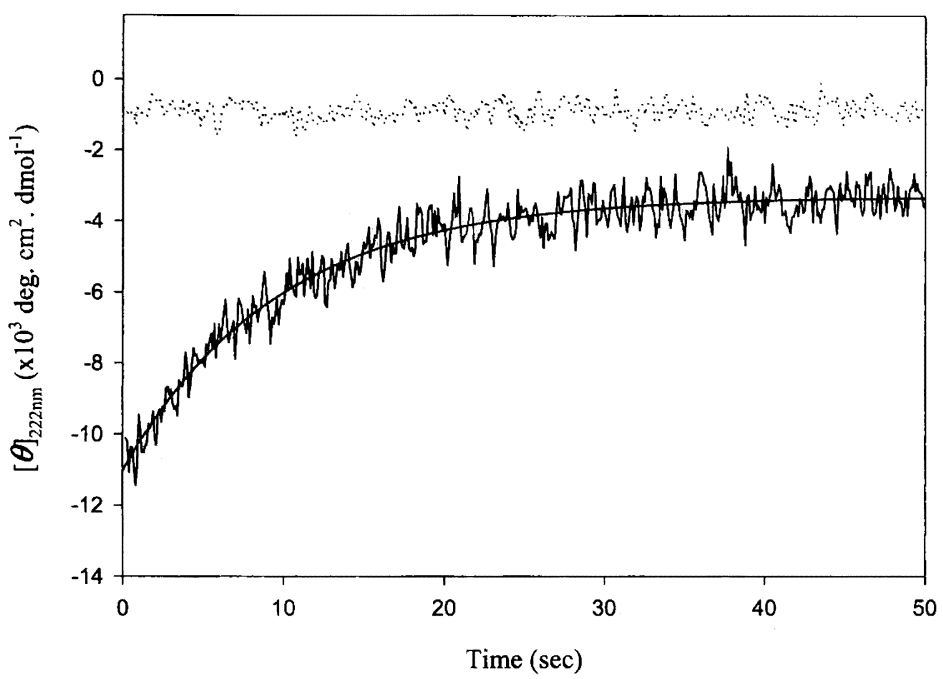

Fig. 5. Refolding of the src SH3 domain in $45 \%$-EGOH, $40 \mathrm{mM}$ PBS, $\mathrm{pH} 3.0$, at $-20^{\circ} \mathrm{C}$. The refolding was initiated by a concentration jump from $5.0 \mathrm{M} \mathrm{Gdn}$. $\mathrm{HCl}$ to $0.71 \mathrm{M} \mathrm{Gdn}$. $\mathrm{HCl}$. The final concentration of SH3 was $20 \mu \mathrm{M}$.

observed by stopped-flow $\mathrm{CD}$ at subzero temperatures, in which the folding rate was significantly slowed down ${ }^{3,4}$. These observations are not surprising in the case of $\beta$-lactoglobulin, since its tendency to form $\alpha$-helical structure is predicted from its amino acid sequence and computer simulation, and has been reported in aqueous solution ${ }^{16)}$. However, the accumulation of a intermediate with non-native $\alpha$-helical structures from the early folding stage of src SH3 domain, an all- $\beta$-structure protein not predicted to form $\alpha$-helical structure, indicates that the $\alpha$-helical structure may be a common, non-specific conformational transition at the beginning of protein folding due to local interactions. There is an argument that the $\alpha$-helical burst might be induced by ethylene glycol (anti-freeze). We have also measured the refolding of src SH3 at $4^{\circ} \mathrm{C}$ in aqueous solution. Results gave also the burst-phase of which amplitude was independent of ethylene glycol or temperature [unpublished data], as it was the case of ubiquitin ${ }^{5}$.

It has been argued that "burst-phase" signals, sometimes observed in the dead-time of stoppedflow refolding kinetics may be due to the response of the unfolded state to the new, poorer solvent conditions rather than the formation of a distinct interme- diate, or to experimental artifacts ${ }^{17-20)}$. However, the observation of the overshoot of the ellipticity at $222 \mathrm{~nm}$ from the burst-phase of three $\beta$-sheet proteins, with far-UV circular dichroism spectra typical of $\alpha$-helix, but not with other proteins (unpublished data) is most readily explained by formation of transient $\alpha$-helical structures. The commonality to three quite different $\beta$-structure proteins, suggests that this could be a general feature of the initial collapse of the expanded unfolded polypeptide chain. Regardless, the question also arises as to whether the observed $\alpha$-helix-rich transient intermediate is actually directly on the folding pathway, or a rapidly formed, off-pathway intermediate, that subsequently is recruited as a starting point for productive folding to the beta-rich final native state.

\section{References}

1) Levinthal, C.: Are there pathways for protein folding? J Chem Phys, 65: 44-45, 1968.

2) Dill, K.: Theory for the folding and stability of globular proteins. Biochemistry, 24: 1501-1509, 1985.

3) Qin, Z-J., Hu, D-M., Shimada, L., Nakagawa, T., Arai, M., Zhou, J-M. and Kihara, H.: Refolding of $\beta$-lactoglobulin studied by stopped-flow circular dichroism at subzero temperatures. FEBS Lett, 507: 299-302, 2001. 
4) Qin, Z., Ervin, J., Larios, E., Gruebele, M. and Kihara, H.: Formation of a compact structured ensemble without fluorescence signature early during ubiquitin folding. J Phys Chem B, 106: 13040-13046, 2002.

5) Larios, E., Li, J. S., Schulten, K., Kihara, H. and Gruebele, M.: Multiple probes reveal a native-like intermediate during low-temperature refolding of ubiquitin. J Mol Biol, 340: 115-125, 2004.

6) Yu, H., Rosen, M. K., Shin, T. B., Seidel-Dugan, C., Brugge, J. S. and Schreiber, S. L.: Solution structure of the SH3 domain of Src and identification of its ligandbinding site. Science, 258: 1665-1668, 1992.

7) Musacchio, A., Gibson, T., Lehto, V. P. and Saraste, M.: $\mathrm{SH} 3$ - an abundant protein domain in search of a function. FEBS Lett, 307: 55-61, 1992.

8) Morton, C. J., Pugh, D. J. R., Brown, E. L. J., Kahmann, J. D., Renzoni, D. A. C. and Campbell, I. D.: Solution structure and peptide binding of the $\mathrm{SH} 3$ domain from human Fyn. Structure, 4: 705-714, 1996.

9) Riddle, D. S., Grantcharova, V. P., Santiago, J. V., Alm, E., Ruczinski, I. and Baker, D.: Experiment and theory highlight role of native state topology in $\mathrm{SH} 3$ folding. Nat Struct Biol, 16: 1016-1024, 1999.

10) Grantcharova, V. P. and Baker, D.: Folding dynamics of the src SH3 domain. Biochemistry, 36: 15685-15692, 1997.

11) Grantcharova, V. P., Riddle, D. S. and Baker, D.: Long range order in the src $\mathrm{SH} 3$ folding transition state. Proc NAS, 97: 7084-7089, 2000.

12) Hagen, S. J., Hofrichter, J., Szabo, A. and Eaton, W. A.: Diffusion-limited contact formation in unfolded Cytochrome C: Estimating the maximum rate of protein folding. Proc Natl Acad Sci USA, 93: 11615-11617,
1996.

13) Bieri, O., Wirz, J., hellrung, B., Schutkowski, M., Drewello, M. and Kiefhaber, T.: The speed limit for protein folding measured by triplet-triplet energy transfer. Proc Natl Acad Sci USA, 96: 9597-9601, 1999.

14) Munoz, V., Thompson, P. A., Hofrichter, J. and Eaton, W. A.: Folding dynamics and mechanism of beta hairpin formation. Nature, 390: 196-199, 1997.

15) Munoz, V., Henry, E. R., Hofrichter, J. and Eaton, W. A.: A Statistical mechanical model for Hairpin kinetics. Proc Natl Acad Sci USA, 95: 5872-5879, 1998.

16) Forge, V., Hoshino, M., Kuwata, K., Arai, M., Kuwajima, K., Batt, C. A. and Goto, Y.: Is folding of beta-lactoglobulin non-hierarchic? Intermediate with nativelike beta-sheet and non-native alpha-helix. J Mol Biol, 296: 1039-1051, 2000.

17) Krantz, B. A., Mayne, L., Rumbley, J., Englander, S. W. and Sosnick, T. R.: Fast and slow intermediate accumulation and the initial barrier mechanism in protein folding. J Mol Biol, 324: 359-371, 2002.

18) Qi, P. X., Sosnick, T. R. and Englander, S. W.: The burst phase in ribonuclease $\mathrm{A}$ folding and solvent dependence of the unfolded state. Nature Struct Biol, 5: 882-884, 1998.

19) Sosnick, T. R., Mayne, L. and Englander, S. W.: Molecular collapse: the rate-limiting step in two state cytochrome $\mathrm{c}$ folding. Proteins. Struct. Funct. Genet. 24: 413-426, 1996.

20) Sosnick, T. R., Shtilerman, M. D., Mayne, L. and Englander, S. W.: Ultrafast signals in protein folding and the polypeptide contracted state. Proc Natl Acad Sci USA, 94: 8545-8550, 1997. 